\title{
Capsule Commentary on Clair et al., The Effect of Cigarette Smoking on Diabetic Peripheral Neuropathy: A Systematic Review and Meta-Analysis
}

\author{
Srinivas Mummadi, M.D., F.C.C.P. \\ Division of Pulmonary and Critical Care Medicine, Tuality Healthcare/Oregon Health \& Science University, Hillsboro, OR, USA.
}

J Gen Intern Med 30(8):1192

DOI: $10.1007 / \mathrm{s} 11606-015-3388-1$

(C) Society of General Internal Medicine 2015

I n this study, Clair et al. use a systematic review and metaanalysis to describe and quantify the association between smoking and a microvascular complication of diabetes - diabetic peripheral neuropathy (DPN). The odds of being a smoker were higher in patients who developed DPN. ${ }^{1}$ This was observed in prospective studies that adjusted for covariates (HbA1c etc.), that studied type 1 patients ( $n=3854$ ), and that had a follow-up period of $\geq 5$ years. It was not seen among type 2 diabetics ( $n=1317$ patients) and with a follow-up period $<5$ years.

Smoking has been identified as a risk factor for progression of microvascular complications in type 1 and nephropathy in type 2 diabetes. ${ }^{2,3}$ It is thought to be a risk factor for development of type 2 diabetes mellitus (DM). ${ }^{4}$

The relationship between smoking and other microvascular complications (retinopathy, neuropathy) in type 2 DM is unclear. In fact, one of the largest prospective studies ( $n=903$ patients) concluded that smoking might offer "protection" against development and progression of retinopathy. ${ }^{5}$ A similar signal of "protection" could be inferred from this study's analyses of type $2 \mathrm{DM}$ patients, although it could also be argued that the analysis was underpowered.

Prospective studies that are suitably powered are needed in type 2 diabetes patients. If this signal of "protection" is replicated, it certainly opens up avenues for investigating novel compounds for treating a costly complication. It also raises the question, "Does the natural history of microvascular complications differ between patients with type 1 and type 2 diabetes?". The association seen in type 1 patients, combined with its propensity to worsen insulin resistance in type 2 patients, should serve as some among the many reasons to encourage tobacco cessation in our diabetic patients. Further studies are needed to define risk factors and to understand the epidemiology of this debilitating condition. This study adds to the wealth of evidence suggesting smoking as a risk factor for the development of DPN in patients with type 1 diabetes and raises important questions about DPN in type 2 patients.

Conflict of Interest: The author has no conflicts of interest with this article.

Corresponding Author: Srinivas Mummadi, M.D., F.C.C.P.; Division of Pulmonary and Critical Care MedicineTuality Healthcare/Oregon Health Science University, Hillsboro, OR 97124, USA (e-mail: Srinivas.Mummadi@tuality.org).

\section{REFERENCES}

1. Clair C, Cohen MJ, Eichler F, Selby KJ, Rigotti NA. The effect of cigarette smoking on diabetic peripheral neuropathy: a systematic review and metaanalysis. J Gen Intern Med. doi:10.1007/s11606-015-3354-y.

2. Biesenbach G, Grafinger $\mathbf{P}$, Janko $\mathbf{O}$, Zazgornik J. Influence of cigarettesmoking on the progression of clinical diabetic nephropathy in type 2 diabetic patients. Clin Nephrol. 1997;48(3):146-50.

3. Chaturvedi N, Stephenson JM, Fuller JH. The relationship between smoking and microvascular complications in the EURODIAB IDDM complications study. Diabetes Care. 1995;18(6):785-92.

4. Willi C, Bodenmann P, Ghali WA, Faris PD, Cornuz J. Active smoking and the risk of type 2 diabetes: a systematic review and meta-analysis. JAMA. 2007;298(22):2654-64.

5. Stratton IM, Kohner EM, Aldington SJ, et al. UKPDS 50: risk factors for incidence and progression of retinopathy in type II diabetes over 6 years from diagnosis. Diabetologia. 2001;44(2):156-63. 